Case Report

\title{
Conservative management of kienbock's disease in a 24 year old adult : A case report
}

\author{
Sanath Kumar Shetty ${ }^{1}$, Aditya Ballal ${ }^{2} \&$ H. Ravindranath Rai ${ }^{3}$ \\ ${ }^{1}$ Assistant Professor, ${ }^{2}$ Postgraduate, Professor \& HOD ${ }^{3}$, Department of Orthopaedic Surgery, \\ K.S. Hegde M edical Academy, Nitte University, M angalore, Karnataka, India. \\ Correspondence \\ Sanath Kumar Shetty \\ Assistant Professor, Department of Orthopaedic Surgery, K.S. Hegde M edical Academy, \\ Nitte University, Mangalore - 575 018, Karnataka, India. \\ M obile : +919845069383E-mail : sanathkumarshetty@hotmail.com
}

\begin{abstract}
Kienbock's disease also known as Lunatomalacia is a rare disorder involving the lunate. Damage to the lunate can lead to pain, stiffness, and in late stages, arthritis of the wrist. This disease is most common in men between the ages of 20 and 40 and rarely affects both wrists. Here we present a 35 year old male manual labourer who presented to our department with complaints of progressive pain and stiffness of his dominant wrist.

Radiographically he was diagnosed to have Lichtmann class IIIA Kienbock's disease of the left wrist. He was managed with analgesics and wrist physiotherapy. On a review at three months he had an acceptable range of motion of the wrist he was symptom free.
\end{abstract}

This article presents our patients history, radiological findings and management.

Key Words: Lunatomalacia, avascular necrosis, Kienbock.

\section{Introduction}

The aetiology of avascular necrosis of the lunate was first described by Kienbock in $1910^{1}$. There is probably no single cause of avascular necrosis of the lunate. Causes include aberrations in the blood supply (arteries), the blood drainage (veins), and skeletal variations. Skeletal variations associated with this disease include a shorter length of the ulna, one of the forearm bones, and also the shape of the lunate bone itself. Trauma, either single or repeated episodes, may possibly be a factor in some cases. This disease can be found more commonly in people who have medical conditions like lupus, sickle cell anemia, and cerebral palsy.

Stahl ${ }^{2}$ followed the progression of the disease, and a

\begin{tabular}{|c|}
\hline Access this article online \\
\hline Quick Response Code \\
\hline
\end{tabular}
refinement of the system which he proposed is used to grade the condition ${ }^{3}$.

Treatment of Kienbock's disease ranges from conservative measures, usually confined to immobilisation during the acute phase, to such operations as joint levelling ${ }^{4}$ by radial shortening or ulnar lengthening, intercarpal fusion ${ }^{5}$, silastic arthroplasty ${ }^{6}$ and vascularised bone grafts?

\section{Case Report}

A 24 year old manual labourer presented to us with complaints of pain and stiffness of the non-dominant wrist for 6 months. Complete clinical and radiological evaluation was done and function of the wrist was assessed. The scoring of the wrist function was done as per the Mayo wrist score. A score of 50 points was calculated. Radiographs of the wrist antero-posterior and lateral views were taken. The radiographs revealed lunate sclerosis with fragmentation without associated carpal alignment changes this corresponded to class III A of Lichtmann classification (Figure 1). The options for treatment were explained to him and was advised for a radial shortening procedure.

The patient refused any surgical intervention. He was also offered conservative mode of management. The conservative management encompassed exercises of the 
wrist with exercises, heat therapy and wrist mobilization. He opted for conservative line of management. He was started on physiotherapy and exercises. At 4 weeks it was noted that he had gradual improvement in the range of motion of the wrist and improvement of symptoms. The range of motion and function of the wrist was kept on a close watch. At the end of 6 months, the wrist functions improved with a Mayo wrist score of 85 with acceptable range of motion (Figure 2). He had no progression of symptoms. He was able to resume his daily activities with a symptom free wrist.

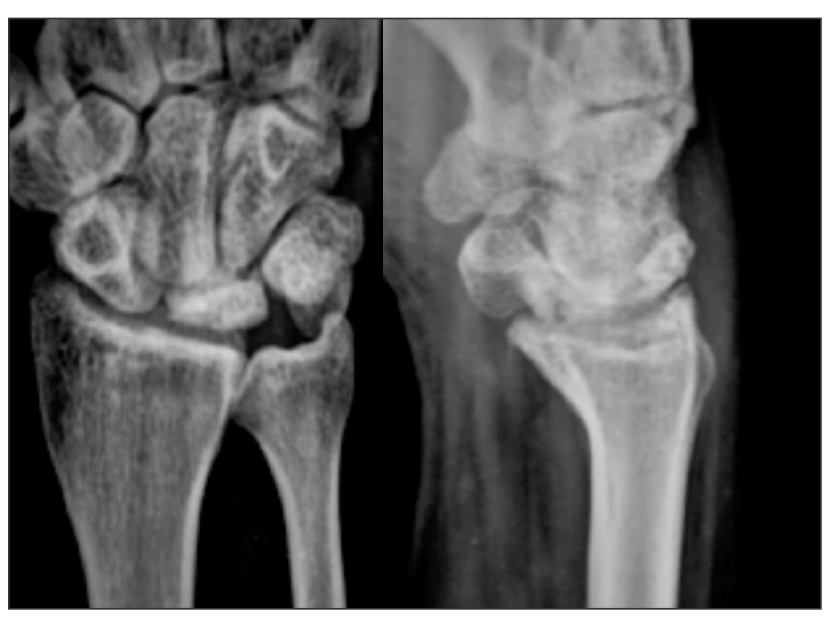

Fig. 1 : AP and Lateral views of the left wrist showing (lunate sclerosis with fragmentation without associated carpal alignment changes).

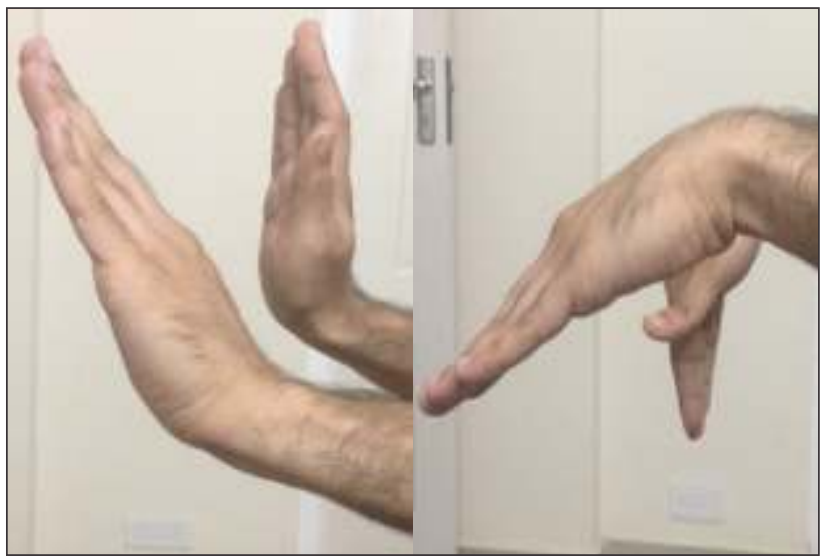

Fig. 2 : Lateral images of the left wrist showing nearly full range of motion of the wrist.

\section{Discussion}

Kienbock's disease also known as Lunatomalacia is a rare disorder involving the lunate. Damage to the lunate can lead to pain, stiffness, and in late stages, arthritis of the wrist $^{1}$.
Since little has been published about the treatment of Kienbock's disease, there are no standards against which results can be compared. Treatment options depend upon the severity and stage of the disease. In very early stages, the treatment can be as simple as observation or immobilization. For more advanced stages, surgery is usually considered to reduce the forces on the lunate bone by lengthening, shortening, or fusing various bones in the forearm or wrist. Surgery can also be aimed at trying to restore blood supply to the lunate (revascularization) ${ }^{7}$, using a bone graft with a blood vessel attached to it. This is not an option in more advanced stages if the relationship of the bones has markedly deteriorated; complete wrist fusion may then be the preferred treatment. Hand therapy does not change the course of the disease; however, hand therapy can help to minimize the disability from the problem. Treatment is designed to relieve pain and restore function.

Beckenbaugh et $\left.a\right|^{8}$ found little difference between the long-term results of patients managed conservatively and those treated by other modalities.

Tajima ${ }^{9}$ had previously published similar findings. Other authors ${ }^{10,11}$ have found conservative treatment either to be ineffective or suitable only for the acute phase of the disease.

The Lichtman classification ${ }^{12}$ :

In stage I radiographs are normal or a linear fracture of the lunate may be visible. In stage II the lunate becomes increasingly radiodense.

In stage IIIA reveals lunate sclerosis with fragmentation without associated carpal alignment changes.

In stage IIIB carpal collapse and fixed scaphoid volar flexion are seen.

In stage IV pancarpal arthrosis exists.

J. Salmon, J. K. Stanley and I. A. Trail reported in their study on comparison of conservative versus surgical management of Kienbock's disease and concluded that patients with stage-2 disease at the time of diagnosis should initially be treated conservatively ${ }^{1}$. 


\section{References}

1. Salmon J, Stanley J.K, Trail I.A, Kienböck's disease conservative management versus radial shortening. The Journal of Bone and Joint Surgery. Vol. 82-B, no. 6, August 2000; 820-823.

2. Stahl F. On lunatomalacia (Kienbo"ck's disease): a clinical and roentgenological study, especially on its pathogenesis and the late results of immobilization treatment. Acta Chir Scand 1947;95 (Suppl 126):3-133.

3. Lichtman DM, Alexander AH, Mack GR, Gunther SF. Kienbo"ck's disease: update on silicone replacement arthroplasty. J Hand Surg 1982;7;343-7.

4. Trail IA, Linscheid RL, Quenzer DE, Scherer PA. UInar lengthen- ing and radial recession procedures for Kienbock's disease: long-term clinical and radiographic follow-up. J Hand Surg [Br] 1996;21:169-76.

5. Graner O, Lopes El, Caralho BC, Atlas S. Arthrodesis of the carpal bones in the treatment of Kienbock's disease, painful ununited frac- tures of the navicular and lunate bones with avascular necrosis, and old fracture dislocations of the carpal bones. J Bone Joint Surg [Am] 1966;48-A:767-74
6. Stark HH, Zemel NP, Ashworth CR. Use of a hand-carved siliconerubber spacer for advanced Kienbock's disease. J Bone Joint Surg [Am] 1981;63-A:1359-70

7. Hori Y, Tamai S, Okuda H, et al. Blood vessel transplantation to bone. J Hand Surg [Am] 1979;4:23-33.

8. Beckenbaugh RD, Shives TC, Dobyns JH, Linscheid RL. Kien- bock's disease: the natural history of Kienbock's disease and con- sideration of lunate fractures. Clin Orthop 1980;149:98-106.

9. Tajima T. An investigation of the treatment of Kienbock's disease. Bone Joint Surg [Am] 1966;48-A:1649.

10. M ikkelsen SS, GelinekJ. Poor function after nonoperative treatment of Kienbock's disease. Acta Orthop Scand 1987;58:241-3.

11. Kristensen SS, Soballe K. Kienbock's disease: the in? uence of arthrosis on ulnar variance measurements. J Hand Surg [Br] 1987;12:301-5.

12. Alexander CA, Turner M, Alexander C, Lichtman RD. Lunate silicone replacement arthroplasty in Kienbock's disease: a long-term followup. J Hand Surg 1990;15A: 401- 407. 